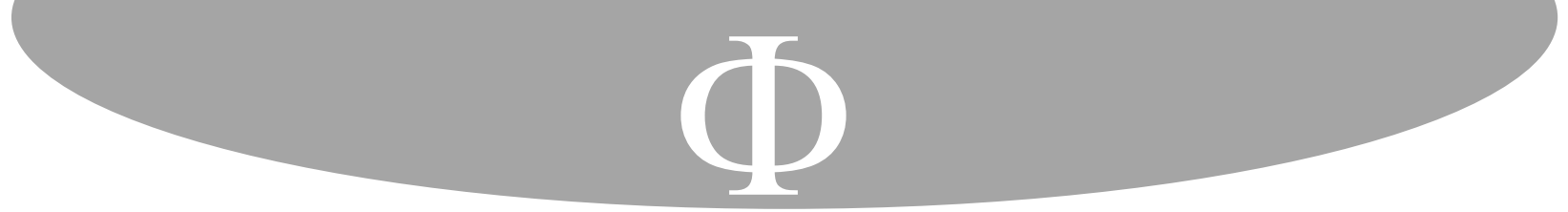

\title{
El libro de los signos (Jn 1,19-12,50). Aproximación a algunas de sus líneas de investigación*
}

\author{
Juan Sebastián Hernández Valencia** \\ Universidad Católica Luis Amigó \\ Universidad Pontificia Bolivariana \\ Medellín, Colombia
}

\begin{abstract}
Para citar este artículo: Hernández Valencia, Juan Sebastián. «El libro de los signos (Jn 1,19-12,50). Aproximación a algunas de sus líneas de investigación». Franciscanum 175, Vol. 63 (2021): 1-28.
\end{abstract}

\section{Resumen}

Es reconocido desde hace tiempo por la crítica que en su estructura y contenido el libro de los signos (Jn 1,19-12,50) comparte cierta semejanza con las secciones iniciales de los tres primeros evangelios. También sus matices teológicos propios han sido resaltados, así como sus fuentes. Este encuentro y diferencia entre el cuarto evangelio y los sinópticos ha divido a los estudiosos respecto al análisis de sus fuentes y sus rasgos teológicos, como lo son el uso de sus fuentes, los relatos de milagros, su escatología y cristología. Este artículo pretende dar una mirada de conjunto a las líneas de investigación más relevantes en estos puntos.

\section{Palabras clave}

Evangelio de Juan, teología joánica, Libro de los signos, cristología joánica, relatos de milagros.

\section{The book of signs (John 1:19-12:50). An approach to some of his currents of research}

\begin{abstract}
It has long been recognized by critics that in its structure and content the Book of Signs (John 1:19-12:50) shares a certain similarity with the initial sections of the first three gospels. It has been also highlighted its own theological nuances, as well as its sources. This

\footnotetext{
${ }^{*}$ El texto sigue la tipología de artículo de reflexión. El texto es producto de investigación del proyecto «Exégesis de la Literatura Cristiana Primitiva» del grupo de investigación Filosofía y Teología Crítica, de la Universidad católica Luis Amigó, con radicado 60577.

** Candidato al doctorado en teología de la Universidad Pontificia Bolivariana, magister en teología y teólogo de la misma universidad. Miembro del grupo de investigación Filosofía y Teología Crítica, de la Universidad católica Luis Amigó; miembro del grupo de investigación Teología, Religión y Cultura (TRyC), de la Universidad Pontificia Bolivariana; miembro de la red de teólogos del CEBITEPAL-CELAM y miembro de la Sociedad Iberoamericana de Antropología Filosófica (SIAF). Contacto: juan.hernandezva@amigo.edu.co y juansebastian.hernandezv@upb.edu.co. ORCID: https://orcid.org/0000-0002-9567-4205.
} 


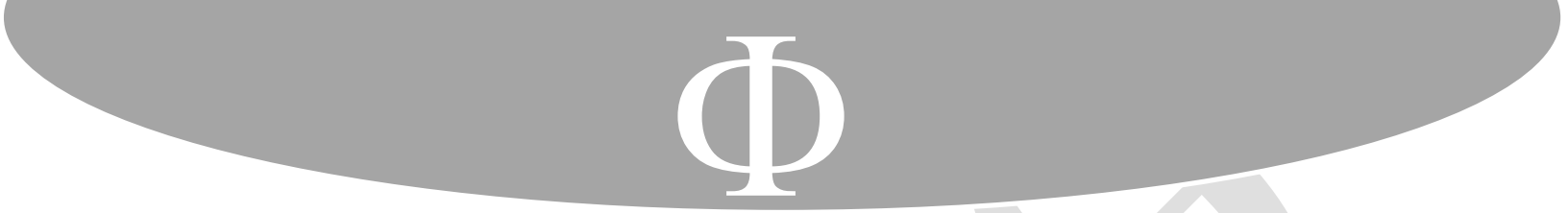

encounter and difference between the Fourth Gospel and the Synoptics have divided the scholars regarding the analysis of its sources and its theological features, such as the use of its sources, the miracles' narratives, its eschatology and christology. This article intends to give an overview of the most relevant lines of research at these points.

\section{Key words}

Gospel of John, theology of John, Book of Signs, Johannine christology, miracles narratives.

El así denominado Libro de los Signos (Jn 1,19-12,50) es la primera sección narrativa del evangelio de Juan ${ }^{1}$. En su estructura y contenido comparte cierta semejanza con las secciones iniciales de los evangelios sinópticos, ya que todos presentan una combinación de narraciones de milagros, escenas de disputa con grupos religiosos judíos sobre la Ley y discursos de Jesús. Aunque con diferencias notables. Mientras los sinópticos comparten rasgos literarios y teológicos similares debido a la utilización de las mismas fuentes (Mc y Q), el EvJn tiene sus propios rasgos literarios y teológicos, y fuentes propias (FS y una fuente propia de discursos), que usa al narrar los milagros y los discursos de Jesús. El análisis de la fuente y la teología del LS ha sido objeto de una gran cantidad de estudios ${ }^{2}$. Este artículo

\footnotetext{
${ }^{1}$ Por el uso contaste de los siguientes términos, en lo sucesivo se emplea la sigla LS para indicar al Libro de los Signos, FS para referir la Fuente de los Signos, y EvJn para denominar al evangelio de Juan.

${ }^{2}$ Sobre la extensa bibliografía, véase los informes y análisis sobre los estudios aparecidos desde 1994 al 2018 , en Michael Labahn, «Literary Sources of the Gospel and Letters of John», en The Oxford Handbook of Johannine Studies, Judith M. Lieu and Martinus C. de Boer, eds. (Oxford: Oxford University Press, 2018), 2731; Udo Schnelle, «Aus der Literatur zum Johannesevangelium 1994-2010 Dritter Teil», ThR 82 (2017): $97-$ 162; Udo Schnelle, «Aus der Literatur zum Johannesevangelium 1994-2010 Zweiter Teil», ThR 78 (2013): 462-504; Udo Schnelle, «Aus der Literatur zum Johannesevangelium 1994-2010 Erster Teil», ThR 75 (2010): 265-303; y Stanley E Porter, Andrew K. Gabriel. Johannine, Writings and Apocalyptic: an Annotated Bibliography (Leiden: Brill, 2013), 57-66. Para los informes y análisis sobre los estudios aparecidos desde 1985 a 1994 véase a Konrad Haldimann y Hans Weder, «Aus der Literatur zum Johannesevangelium 1985-1994. Dritter Teil», ThR 71 (2006): 91-113, 192-218, 310-324; Konrad Haldimann y Hans Weder, «Aus der Literatur zum Johannesevangelium 1985-1994. Zweiter Teil», ThR 69 (2004): 75-115; Konrad Haldimann y Hans Weder, «Aus der Literatur zum Johannesevangelium 1985-1994. Erster Teil», ThR 67 (2002): 328-348, 425456; Robert Kysar, «The Fourth Gospel: A Report on Recent Research», en $A N R W$ II. 25/3, Wolfgang Haase, Hildegard Temporini, eds. (Berlin/New York: Walter de Gruyter, 1985), 2389-2480; y Gilbert van Belle, The Signs Source in the Fourth Gospel (Leuven: Leuven University Press, 1994). En comparación, ha sido menor el análisis de la posible relación y los desarrollos teológicos de la tradición sinóptica con el LS, sobre esto, véase a Santiago Guijarro Oporto, «El Impulso Creativo de la Memoria de Jesús en la Tradición Joánica». Revista Bíblica 75 (2013): 19-24; James D. Dvorak, «The Relationship between John and the Synoptic Gospels», JETS 41 (1998): 201-213; D.A. Carson, «Current Source Criticism of the Fourth Gospel», JBL 97 (1978): 411-429; Raymond E. Brown, «Incidents that are Units in the Synoptic Gospels but Dispersed in St. John», CBQ 23 (1961): 143-160; Ernst Haenchen, «Johanneische Probleme», ZThK 56 (1959): 19-54; E.K. Lee, «St. Mark and the Fourth Gospel», NTS 3 (1959): 50-58; Siegfried Mendner, «Zum Problem „Johannes und die Synoptiker"», NTS 4 (1957-1958): 282-307; Émile Osty, «Les points de contact entre le récit de la passion dans saint Luc et dans saint Jean», RSR 39 (1951): 146-154; y P. Gardner-Smith, Saint John and the Synoptic Gospels (Cambridge: CUP, 1938).

En los últimos años se ha desarrollado una investigación histórica sobre Jesús que parte del cuarto evangelio como fuente, el John, Jesus and History Proyect, liderado por bien conocidos especialistas joánicos como Alan Culpepper, Moody Smith, Paul N. Anderson y Tom Thatcher, entre otros. Si bien este grupo analiza mucho del
} 


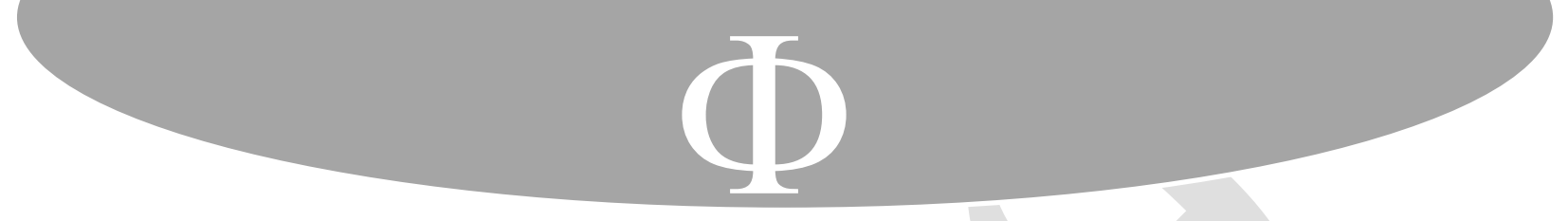

- Una sección de «viaje», indicada por la inclusión con el nombre «Caná» $(2,1-4,54)$.

- Una sección donde se describe la sustitución de las fiestas judías y su plenitud en Jesús (5,1$10,42)$.

- Una sección donde se adelanta el tema del Libro de la Gloria (11,1-12,36).

- Conclusión del ministerio de Jesús (12,37-50).

El LS no solo coincide con Marcos en su esquema narrativo, i.e. con el relato del ministerio de Jesús, sino también con una de sus líneas principales: el tema del rechazo ${ }^{15}$. Por un lado, en esta primera sección narrativa del EvJn se presenta a Jesús atrayendo a diferentes personas. Por otro, en 12,39-40, se cita a Is 6,10 para indicar el tema del rechazo del pueblo, que tiene sus ojos y corazones cerrados ${ }^{16}$. Este desarrollo ya viene adelantado en 1,11 .

Si bien los datos cronológicos y geográficos de la narración son claros y consecutivos en las primeras dos secciones narrativas, i.e. 1,19-51; 2,1-4,54, no lo son tanto para el resto. A pesar de que en 2,23 se enuncia que Jesús ha hecho varios signos en Jerusalén, en 4,54 se dice explícitamente que la curación del hijo del funcionario real es solo su segundo signo después de la boda de Caná (cf. 2,11). Durante todo el capítulo 3 Jesús es ubicado en Jerusalén, no obstante, en 3,22 se indica que él se desplaza hacia Judea. Asimismo, en el

la creación de la comunidad joánica. Sobre este marco cronológico, véase el uso del adverbio e0paurion en 1,29.35.43 en unión con la frase inicial de 2,1: kai th $=$ tri th hmera (siguiendo la lectura de $\mathrm{B}$ Q $\mathrm{f}^{13}$ ). Aunque recientemente Méndez ha objetado la existencia de esta comunidad, entendiéndola como un constructo teórico más que una realidad sociológica. Véase a Hugo Méndez, «Did the Johannine Community Exist?», JSNT 42 (2020): 350-374. Por otro lado, la perícopa de 2,1-12 sirve como engarce entre el tema del capítulo 1 sobre la doca de Jesús con el de los signos de los capítulos 2-4. En Jn 1, doca de Jesús es el tema de los testimonios del Bautista y el objetivo del paulatino reconocimiento de sus discípulos, cuyo clímax se da en 2,12; en Jn 2-4 la doca de Jesús también es el tema de los signos, los diálogos, los discursos y todo el esquema de viajes de la subsección. El tema y objetivo de estos capítulos es el mismo, pero su instrumento narrativo varia. Esta es la razón por la cual no se puede enfatizar en una diferencia de fondo, sino de subtemas. De hecho, en 3,22-30, se continúa con el tercer testimonio del Bautista, el instrumento narrativo para la revelación de la doca de Jesús durante todo el capítulo primero. Parece mejor entender la perícopa de 2,1-12 como un puente entre una y otra subsección. Pero también es importante diferenciar los instrumentos narrativos de cada subsección. Por ello se insiste en segmentar entre 1,19-51 y 2,1-4,54. Sobre el tema de la revelación de la doca de Jesús en los testimonios del Bautista, véase a Ulrich B. Müller, Johannes der Täufer (Leipzig: Evangelische Verlagsanstalt, 2002), 163-167. Sobre el esquema cronológico de Jn 1,19-2,1 y su teología, véase a Jeannine K. Brown, «Creation's Renewal in the Gospel of John», CBQ 72 (2010): 275-290; Harold Saxby, «The Time-Scheme in the Gospel of John», ExpTim 104 (1992): 9-13; L. Paul Trudinger, «The Seven Days of the New Creation in St. John's Gospel. Some Further Reflections», EQ 3 (1972): 154-158; y Thomas Barrosse, «The Seven Days of the New Creation in St John's Gospel», $C B Q 21$ (1959): 507-516. Francis J. Moloney (El Evangelio de Juan [Estella: EVD, 2005], 75-76) encuentra relación léxica y teológica entre la primera semana joánica con el tema de la doca de YHWH de los relatos del Éxodo. Brown (Juan I-XII, 328-330) duda sobre la interpretación de la primera semana joánica.

${ }^{15}$ Sobre el rechazo en el evangelio de Marcos, véase a W.R. Telford, The Theology of the Gospel of Mark (Cambridge: CUP, 1999), 116-137. Smith hace un valioso análisis del tema del rechazo marcano desde el patrón lírico y literario del drama griego. Véase S.H. Smith, «A Divine Tragedy», en The Composition of Mark's Gospel (David E. Orton, comp. Leiden/Boston/Köln: Brill, 1999), 230-252.

${ }^{16}$ Véase a Craig A. Evans, To See and Not Perceive: Isaiah 6.9-10 in Early Jewish and Christian Interpretation (Sheffield: JSOT Press, 1989), 91-106. 


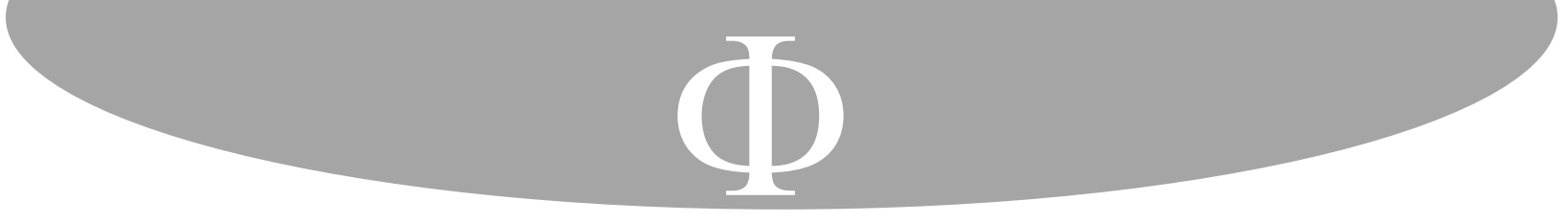

las señales en 2,11 y 4,54, y la referencia de las señales en la conclusión del EvJn (20,30; 21,25).

En el NT, el vocablo $\sigma \eta \mu \varepsilon ı$ ( («igno, señal») aparece 77 veces $^{29}$. De estas, el plural, empleado por Juan, aparece un total de 32 veces en el NT; siendo Juan y Lucas quienes más lo usa $^{30}$. En ninguno de los pasajes sinópticos el vocablo $\sigma \eta \mu \varepsilon \imath \alpha$ está relacionado con los milagros. De hecho, el vocabulario sinóptico de los milagros emplea vocablos como $\tau \varepsilon \rho \alpha \varphi$. En el resto del NT, $\sigma \eta \mu \varepsilon 1 \alpha$ hace parte del vocabulario escatológico. Esto es especialmente significativo en el caso de los sinópticos (cf. Mt 16,3; 24,24; Mc 13,22; 16,17; Lc 21,11.25). Algunos autores han notado la cercanía que Lucas presenta con el vocabulario joánico, viendo el uso sistemático de su fórmula $\tau \varepsilon \rho \alpha \tau \alpha \kappa \alpha \iota \sigma \eta \mu \varepsilon \iota \alpha(« \text { portentos y señales»)})^{31}$.

Los especialistas creen que existió una colección de milagros de Jesús que circulaba en la comunidad joánica antes de la redacción del EvJn. Dicha colección en parte fue absorbida en el evangelio. Los esfuerzos por reconstruir tal fuente de signos o señales han arrojado resultados dispares ${ }^{32}$. Por un lado, algunos piensan que la fuente no solo contenía los relatos de milagros presentes en el evangelio, sino también el relato de vocación de los discípulos $(1,19-51)^{33}$ y la historia de la Pasión (capítulos 18-20) ${ }^{34}$. Por otro lado, está la sugerencia que explica que la fuente solo contendría la narración consecutiva de siete milagros o incluso solo los milagros numerados entre los capítulos 2-4 y $21^{35}$.

Desde la primera edición de su comentario, Bultmann dio la forma clásica a la hipótesis de la FS. También reconoció varios precursores, notablemente a Faure ${ }^{36}$. Él no desarrolló los criterios para la separación de la fuente pre-joánica de la redacción final, ni precisó el contenido concreto de la fuente. Estas falencias han sido suplidas en el trabajo de van Belle ${ }^{37}$. Algunos aspectos de la propuesta de Bultmann han sido menos convincentes que otros. Sin embargo, nadie que ha trabajado en la hipótesis de la FS ha ignorado el trabajo de Bultmann. De hecho, desde un principio ganó amplia aceptación, especialmente en Alemania

\footnotetext{
${ }^{29}$ En Mt, 13 veces; Mc, 7 veces; Lc-Hch, 24 veces; Jn, 17 veces; Rom, 2 veces; 1-2Cor, 4 veces; 2 Tes, 2 veces; Heb, 1 veces; y en Ap, 7 veces. Sobre estas estadísticas, véase a Kurt Aland (ed.), Vollständige Konkordanz zum Griechischen zum Neuen Testament. Tomo 2: Spezialübersichen (ANTT 4/1-2. New York/Berlin: Walter De Gruyter), 1978), 248-249.

${ }^{30}$ En Mt, 2 veces; Mc, 2 veces; Lc-Hch, 12 veces; Jn, 10 veces; 1-2Cor, 2 veces; y en Ap, 4 veces.

${ }^{31}$ En algunos pasajes aparece la formula invertida shmeia kai terata; véase Hch 2,19.43; 4,30; 5,12; 6,8; 7,36; 14,$3 ; 15,12$; obsérvese también la aparición de la frase lucana shmeia kai terata en Jn 4,48. Sobre los autores que hacen estas observaciones, véanse las notas al pie de página 10 y 11.

${ }^{32}$ W. Nicol, The Sémeia in the Fourth Gospel: Tradition and Redaction (Leiden: Brill, 1972).

${ }^{33}$ Jürgen Becker, «Wunder und Christologie», NTS 16 (1970): 130-148.

${ }^{34}$ Robert T. Fortna, The Gospel of Signs (Cambridge: CUP, 1970).

${ }^{35}$ Hans -P. Heekerens, Die Zeichen-Quelle der johanneischen Redaktion (Heidelberg: Verlag Katholisches Bibelwerk, 1984).

36 Alexander Faure, «Die alttestamentlichen Zitate im vierten Evangelium und die Quellenscheidungshypothese», ZNW 21 (1922): 99-121. Bultmann también reconoce cierto mérito a Eduard Meyer, Ursprung und Anfänge des Christentums. Erster Band: Die Evangelien (Stuttgart/Berlin: J.G. Cotta, 1921), 337.

${ }^{37}$ Gilbert van Belle, The Signs Source in the Fourth Gospel (Leuven: Leuven University Press, 1994).
} 


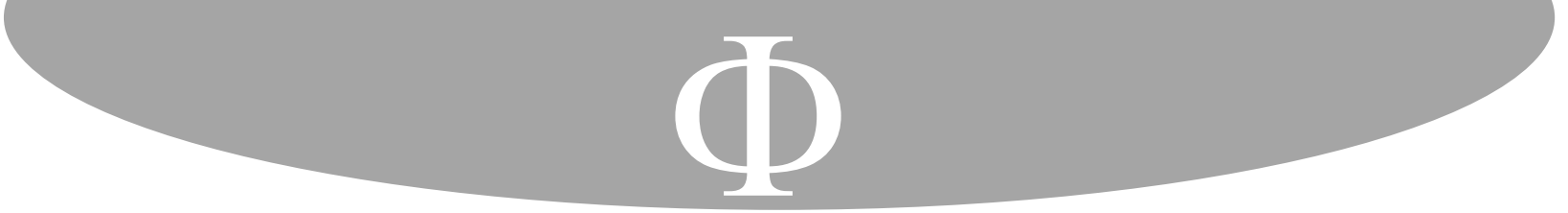

Esta misma consciencia de la íntima relación con el Padre es presentada en el EvJn por medio de las constantes afirmaciones del Jesús joánico: «el Padre y yo somos uno» (10,30); y: «en verdad en verdad os digo que el Hijo no puede hacer nada por su cuenta, sino lo que ve hacer al Padre: lo que hace él, eso hace igualmente el Hijo» $(5,19$; cf. 3,35). Estas afirmaciones cuestionaban el dogma básico del judaísmo del segundo templo: el monoteísmo radical (cf. Dt 6,4$)^{79}$. Y en el desarrollo de la creciente relación tirante entre Jesús y los «judíos», tales afirmaciones sobre su íntima filiación con el Padre son entendidas como blasfemia (cf. 5,18; 10,33).

Según Wilckens, solo en la cristología joánica se encuentra una crisis tan profunda frente al dogma monoteísta radical del judaísmo de la época ${ }^{80}$. Asimismo, como en la tradición sinóptica, el título cristológico «Hijo de Dios» en la tradición joánica parece

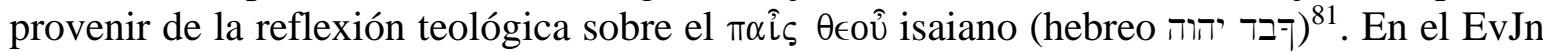
este título pierde un poco la referencia explícita a la soteriología de los relatos sinópticos de la Pasión y su figura del siervo sufriente, ya solo rastreable en la conexión en el prólogo entre el logos y su rechazo (cf. Jn 1,10-11). En los sinópticos este título es aplicado a Jesús, no solo como siervo sufriente, sino también entendiendo al $\pi \alpha \hat{\imath} \varsigma$ como Hijo, aplicando tal comprensión a los relatos de la vocación de Jesús (cf. Mc 1,9-11) ${ }^{82}$.

Asimismo, las narraciones evangélicas sobre el sistemático rechazo a la cristología alta parecen contar la historia del fracaso del reconocimiento mesiánico que el Jesús histórico vivió. En los sinópticos, esta historia se presenta in crescendo: primero los grupos religiosos y las autoridades, representadas en las nominaciones colectivas: los fariseos (Mt 9,11); los escribas y los fariseos (Lc 5,17.21.30); los fariseos y los herodianos (Mc 3,6; 8,15; 12,13); los fariseos y los saduceos (Mt 16,11-12); los fariseos y los sacerdotes (Mt 21,45); y los fariseos y todos los judíos (Mc 7,3). En el EvJn pocas veces se utilizan estas denominaciones colectivas, como en 1,19. Esto se debe en parte a la predilección de Juan por el uso del

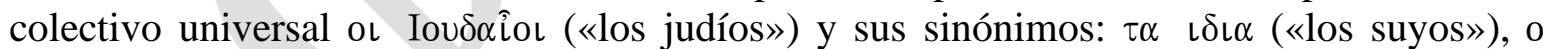

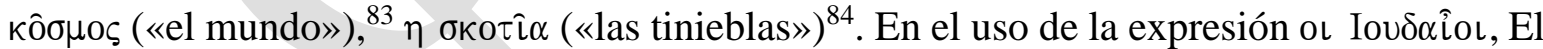
EvJn parece estar cerca de Mc 7,3. Se suele explicar semejante utilización de generalizaciones, que hoy son percibidas con mucha sensibilidad por la corrección política como excesivamente antisemitas, por la situación histórica del rechazo generalizado, la

\footnotetext{
${ }^{79}$ Sobre esto, véase particularmente el tratamiento de Larry W. Hurtado, «The Origins of Jesus-Devotion». TynBul 61 (2010): 1-20; y Gerd Theissen, La Religión de los Primeros Cristianos (Salamanca: Sígueme, 2002), 223-245.

${ }^{80}$ Ulrich Wilckens, Der Sohn Gottes und seine Gemeinde, 126-135.

${ }^{81}$ Sobre esto, véase a Craig A. Evans, «Obduracy and the Lord's Servant», en Early Jewish and Christian Exegesis (Craig A. Evans, W.F. Stinespring, eds. Atlanta, GE: Scholars Press, 1987), 221-236.

${ }^{82}$ Véase a Joachim Jeremias, Abba: El Mensaje Central del Nuevo Testamento, 113-151.

${ }^{83}$ Sobre el concepto ko/smoj en el EvJn, véase a Cornelis Bennema, «The Identity and Composition of OI IOUDAIOI in the Gospel of John», TynBul 60 (2009): 239-263; Lars Kierspel, The Jews and the World in the Fourth Gospel (WUNT II/220. Tübingen: Mohr Siebeck, 2006); y Ulrich Wilckens, Der Sohn Gottes und seine Gemeinde, 126-135.

${ }^{84}$ Véase los paralelos entre Jn 1,5.10.11.
} 


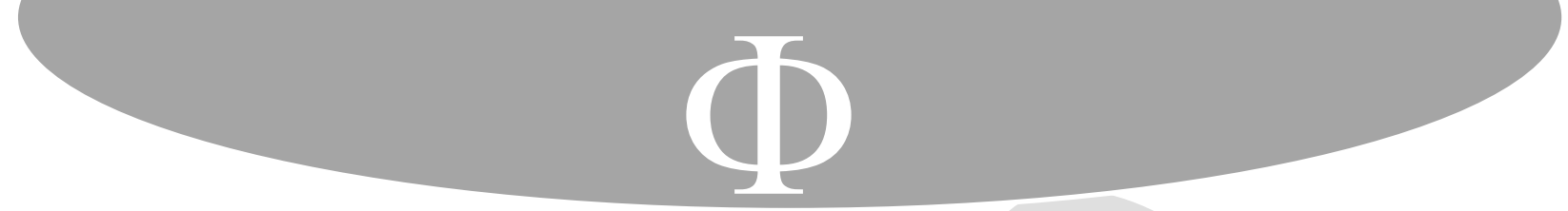

En este texto se debe notar que el verbo hebreo pa significa generalmente «adquirir» ${ }^{90}$. Se trata de una adquisición por medio del nacimiento: «engendrar» (cf. Gen 4,1;

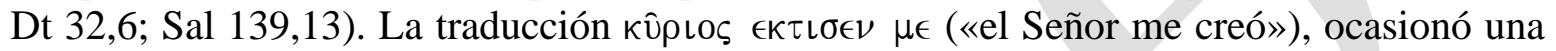
seria dificultad con los arrianos, que empleaban este texto para defender la naturaleza creada del logos. La traducción de san Jerónimo: Dominus possedit me («el Señor me poseyó»), refleja las de Aquila, Símaco y Teodoción ${ }^{91}$; y recuerda el agudo comentario de Basilio:

No obstante, no he querido guardar silencio sobre esto, ya que otros intérpretes han

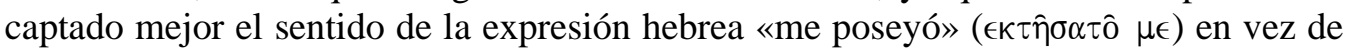
«me creó» $(\epsilon 1 \kappa \tau \iota \sigma \in \nu)$. Esto ha sido para ellos (los arrianos) el mayor impedimento contra la blasfemia de su interpretación creatural. Porque el que dijo: «He engendrado un hombre por medio de Dios», empleaba obviamente la expresión no como creador de Caín, sino como su engendrador (Contra Eunomium, 2, 20 [PG 29, 616-617]) ${ }^{92}$.

Según Brown, tales argumentaciones parecerían inadecuadas, puesto que en la cristología joánica, una de las características fundamentales del logos es la preexistencia. Esta preexistencia es importante no solo para defender la posición superior que Jesús tiene ante Juan el Bautista, sino también para resaltar su función de creador ${ }^{93}$. Desde la perspectiva de la teología desarrollada por el EvJn, resulta evidente el papel subordinado de Juan el Bautista. Esta subordinación ha tenido su espacio en la apologética cristiana primitiva y apostólica, por ejemplo, las acusaciones de Celso y las réplicas de Orígenes (Contra Celsum, I, 40-47 $)^{94}$. Desde un plano estrictamente teológico, la defensa de la preexistencia del logos implica la defensa de su carácter esencialmente divino: si es creador, no es creatura. Su

\footnotetext{
${ }^{90}$ Sobre las posibles traducciones de yninFqf (el verbo hnq + el sufijo $1 \mathrm{p} . \mathrm{m}$. sg.): en qal (que es la que suponemos aquí), en niph'al («ser comprado») y el hiph'îl («intercambiar»), véase a Otto Plöger, Sprüche Salomos (Proverbia) (BKAT 17. Neukirchen-Vluyn: Neukirchener, 1984), 87; y Jean -Nöel Aletti, «Proverbes 8,22-31: Étude de structure», Bib 57 (1967): 25-37 y pp. 31-32. En Gen 4,1b se presenta un problema de interpretación similar al que aquí se observa: hwFhy:-t)e \#\$y)i yt@yniqf rme)Ot@wa: «he (creado, adquirido, engendrado) un hombre (con la ayuda de, con, para) YHWH». Véase lo que se ha estudiado con algo más de detalle en: Juan Sebastián Hernández Valencia, «¿Un Juicio Justo contra Caín? (Gen 4,1-16)», Caritas Veritatis 2 (2017): 150-151, y la bibliografía que allí se cita.

91 Véase los textos de estas versiones griegas en Frederick Field, Origenis Hexaplorum. Tomus II: Jobus Malachias (Oxford: Clarendon Press, 1875), 875 y 326.

${ }^{92}$ La traducción castellana ofrecida arriba es propia. Por su importancia, se reproduce el texto griego citado arriba: Te/wj ge mh_n mhde e0kei=no aparash/manton katali/pwmen oti alloi tw n ermhne/wn, oi kairiw\&teron th=j shmasi/aj tw n Ebrai"kw n kaqiko/menoi, e0kth/sato/ me anti tou=, ektisen e0kdedw\&kasin: Oper me/giston autoi=j empo/dion estai pro_j th_n blasfhmi/an tou= kti/smatoj. O ga_r eiOpw_n, ekthsamhn anqrwpon dia_tou=qeou=, ou0xi kti/saj to_n Kai"n, alla_gennh/saj, tau/th| fai/netai xrhsa\&menoj th|= fwnh|=. Sobre el texto, véase la edición y traducción francesa de Bernard Sesboüé, George -M. De Durand, Louis Doutreleau, Basile de Césarée. Contre Eunome. Introduction, traduction et notes (SC 299. Paris: Éditions du Cerf, 1983), II, 84-85.

${ }^{93}$ Raymond E. Brown, La Comunidad del Discípulo Amado (2 ed. Salamanca: Sígueme, 1987), 30-31.

${ }^{94}$ No obstante, en el caso de Orígenes, el tema central de su exposición no es la relación entre el Bautista y Jesús, sino el Bautismo de Jesús. Orígenes enfrenta la acusación de Celso de zoomorfización de la divinidad (el Espíritu Santo en forma de paloma). Sobre esta polémica, véase a Wayne C. Kannaday, Apologetic Discourse and the Scribal Tradition (SBLTCS 5. Atlanta, GE: SBL, 2004), 78. Véase el texto en Marcel Borret, Origène. Contre Celse (SC 132. Paris: Les Éditions du Cerf, 2005) I, 183-201.
} 


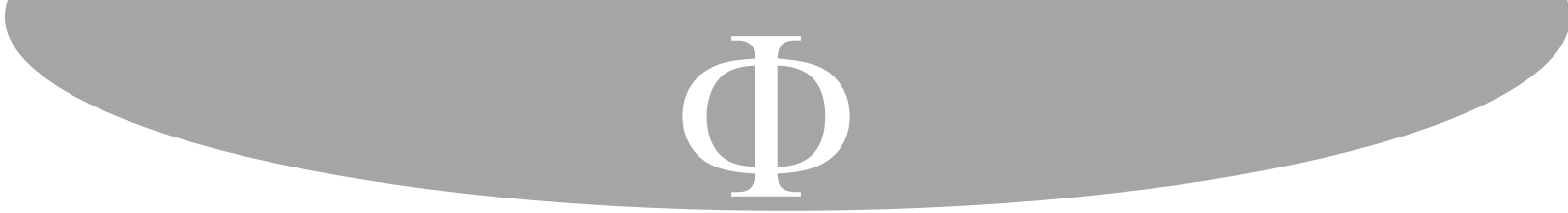

Trudinger, L. Paul. «The Seven Days of the New Creation in St. John's Gospel. Some Further Reflections». EQ 3 (1972): 154-158.

Tuckett, Christopher M. Revival Griesbach Hypothesis. SNTSMS 44. Cambridge: CUP, 1982.

Van Belle, Gilbert. The Signs Source in the Fourth Gospel. Leuven: Leuven University Press, 1994.

Van Belle, Gilbert. comp. Johannine Bibliography. 1966-1985. Leuven: Peeters, 1988.

Vielhauer, Philipp. Geschichte der urchristlichen Literatur. Berlin/New York: Walter De Gruyter, 1975.

Waddell, James A. The Messiah. London: T. \& T. Clark, 2011.

Walck, Leslie W. The Son of Man in the Parables of Enoch and in Matthew. New York: T. \& T. Clark, 2011.

Wick, Peter. «Jesus gegen Dionysos? Ein Beitrag zur Kontextualisierung des Johannesevangeliums». Bib 85 (2004): 179-198.

Wilckens, Ulrich. Der Sohn Gottes und seine Gemeinde. FRLANT 200. Göttingen: Vandenhoeck \& Ruprecht, 2003.

Wilkens, Wilhelm. Die Entstehungsgeschichte des vierten Evangeliums. Zollikon: Evangelischer Verlag, 1958.

Wrede, W. Das Messiasgeheimnis in den Evangelien. 4 ed. Göttingen: Vandenhoeck \& Ruprecht, 1969.

Enviado: 8 de junio de 2020

Aceptado: 28 de junio de 2020 